\title{
TRAINING PROGRAM FOR MILITARY STUDENTS FOR THE IMPROVEMENT OF THE FREESTYLE SWIMMING METHOD
}

\author{
Fabiana MARTINESCU-BĂDĂLAN, Ramona-Elena HERMAN \\ "Nicolae Bălcescu" Land Forces Academy, Sibiu, Romania \\ martinescu_fabiana@yahoo.com, ramoherman@gmail.com
}

\begin{abstract}
In this paper we wanted to demonstrate that improving swimming performance, even over a short period of time, requires a centralized training program. The subjects of the research were checked on a distance of $50 \mathrm{~m}$ freestyle before and after the application of the centralized training program, and the results were compared with those from the control group who did not benefit from the centralized training program, the latter ones having participated only in the classes of the approved syllabus. All the results from the research were interpreted objectively, the resulting figures being the actual support of this study. The tests and the program applied proved relevant in view of the purpose of this study.
\end{abstract}

Keywords: swimming, freestyle, program, training

\section{Introduction}

Swimming is a sport that brings a lot of physical, social and mental benefits. Swimming tones up the muscles and at the same time is a very good cardiovascular workout. Swimming increases heart rate and stimulates circulation, is a sport that involves all muscle groups. It is an ideal sport for a good overall health and fitness. It increases muscle strength, flexibility and makes visible improvements to the posture also does not exert pressure on the joints. When we swim without proper technique, there is a great deal of waste of energy. The truth is that you have a good overall fitness state, but for this, you burn too much calories and keep your heart rate too high. But these things do not make you a better swimmer.

„Freestyle is a natural, cyclical cross movement. It has the least steep body position, so it has the minimum of front resistance, consequently it is the fastest style." [1]
The process is based on the "over" swimming style where the swimmer slides across the water lying on one side and side-stroking with one arm.

From this style to today's "freestyle", several world-class swimmers have brought their contribution, of which we mention Johny Weismüller (the first freestyle swimmer to fall below 1 minute per 100 m), Dawn Fraser, Michael Gross, Rolands Mattes, Mark Spitz, Jim Montgomery, Alexandru Popov.

Main features of the free (freestyle) swimming method:

$>$ The execution of the foot stroke must be very effective, a minimum of long beats being recommended, without speed being negatively influenced;

$>$ Speed will be maintained constantly over the swimming distance;

$>$ The arms must be coordinated with the movements of the head and legs, making quick movements; 
$>$ The swimmer's body is spread over the surface of the water, the arms are in the extension of the body;

$>$ The head will look ahead, submerged to the level of the eyebrows;

$>$ The legs are kept under water to ensure good float, the shoulders should be as close as possible to the surface of the water, to reduce the resistance to advancing and the basin is slightly raised;

$>$ The body will form an angle of about 100 degrees with the surface of the water (the tip being at the level of the shoulders);

$>$ The body position in freestyle swimming differs for the swimmers preparing for speed tests or those who prepare for the open water swimming tests.

In preparing a training program, whether we are talking about children, juniors, youth or seniors, we have to respect the basic pedagogical principles "from the known to the unknown, from easy to difficult, from simple to complex". In addition to this, we need to know the methods and means of training as well as their strict applicability among the teams of individuals with whom we are working. Swimming with a good technique of freestyle stroke is a desire that many expect. Whether it is for competition, triathlon or just to feel and look good in the pool, freestyle stroke swimming technique is one of the most desired swimming techniques to be well-mastered by everyone.

Freestyle swimming technique as a swimming technique is the fastest and most effective of all. This is largely due to the optimal position of the body in the water, as well as the continuous propulsion of the arms and legs. The constant action of the arms generates almost all of the propulsion and is the most effective arm action of the four swimming techniques (freestyle stroke, breaststroke, butterfly stroke, backstroke). The action of the feet supports a horizontal position of the body, optimized, and balances the action of the arms, but offers a little propulsion.

„(...) the freestyle breathing is the most difficult one out of the four styles(...).Competitive swimmers develop their breathing rhythm in accordance with the distance and their individual abilities. Short-course swimmers swim holding their breath, or they breathe once or twice on 50 meters. Long-course swimmers also use the double or alternating breathing." [2]

\section{Methods used}

It should be known that there are several ways to record swimming performance.

The first criterion that is most widespread and the one that all swimmers take into account is the number of laps covered. This is possible when working on relatively short distances, and when the pool in which you swim is an Olympic one, otherwise it is a terrible hassle during a workout to remember the covered laps.

The pace, or the tempo that you have in the pool. If runners measure their time in $\mathrm{km} /$ minute, the unit of measurement is the number of minutes covered per hundred meters.

The number of strokes: it can be counted in two forms, namely the number of strokes in a minute or the number of strokes made along the length of a pool. If the figure is small the swimming is done at a too slow pace, if it is too high, the pace is fast.

SWOLF - in translation, Swim (swimming) gOLF (golf). It is an indicator that combines speed and effort, number of arm strokes in the pool along with the number of seconds. (For example, if you swim a semi-Olympic pool length (25 meters) in 24 seconds, making 18 arm strokes, your SWOLF score will be 42). We want this score to be the lowest possible.

The SWOLF score is the easiest way to measure the swimmer's overall efficiency. In this paper we used the PACE recording seconds on a $50 \mathrm{~m}$ freestyle swimming distance. 
Didactic design in order to achieve the objectives

„The Crawl and Trudgeon Crawl are by all means the fastest strokes for propelling the human body through the water up to

date."[3]

The time spent on preparing for the experimental group was preset, namely 12 weeks, 4 or 6 hours each week; 2 hours in the curriculum and 4 hours optional. Subjects in the testing group entered the swimming pool only during the hours of the syllabus. Due to the limited time the testing took place on the distance of $50 \mathrm{~m}$, freestyle stroke. The following results were recorded following the test.

Swimming program adapted for military students:

Week I:

$>$ Warm-up outside the pool 5-10 minutes (gymnastics exercises and active stretching)

$>$ Warm-up in the water $150 \mathrm{~m}$., in the styles known by each individual.

$>$ 50M FREESTYLE STROKE TESTING

$>4$ sets of $50 \mathrm{~m}$ freestyle stroke, medium pace with a 30 seconds break between the sets (emphasis is placed on the coordination of arms and legs movements with breathing)

$>4$ sets of $50 \mathrm{~m}$ breaststroke, medium pace with a 30 seconds break between the sets (emphasis is placed on the coordination of arms and legs movements with breathing)

$>2$ sets of $100 \mathrm{~m}$ freestyle stroke, 45 seconds break (emphasis is placed on the coordination of arms and legs movements with breathing)

$>2$ sets of $100 \mathrm{~m}$ breaststroke, 45 seconds break (emphasis is placed on the coordination of arms and legs movements with breathing)

$>$ Recovery $150 \mathrm{~m}$ breaststroke or backstroke

$>$ Easy stretching outside the pool for 510 minutes

Week II
Warm-up outside the pool 5-10 minutes (gymnastics exercises and active stretching)

Warm-up in the water $150 \mathrm{~m}$., in the styles known by each individual.

4 sets of $50 \mathrm{~m}$ freestyle stroke, medium pace with a 30 seconds break between the sets (emphasis is placed on the coordination of arms and legs movements with breathing)

4 sets of $50 \mathrm{~m}$ breaststroke, medium pace with a 30 seconds break between the sets (emphasis is placed on the coordination of arms and legs movements with breathing)

2 sets of $100 \mathrm{~m}$ freestyle stroke, 45 seconds break

2 sets of $100 \mathrm{~m}$ breaststroke, 45 seconds break

Recovery $150 \mathrm{~m}$ breaststroke or backstroke

Easy stretching outside the pool for 5-10 minutes

Week III

> Warm-up outside the pool 5-10 minutes (gymnastics exercises and active stretching)

$>$ Warm-up in the water $200 \mathrm{~m}$., in the styles known by each individual.

6 sets of $50 \mathrm{~m}$ freestyle stroke, medium pace with a 30 seconds break between the sets (emphasis is placed on the coordination of arms and legs movements with breathing)

$>6$ sets of $50 \mathrm{~m}$ breaststroke, medium pace with a 30 seconds break between the sets (emphasis is placed on the coordination of arms and legs movements with breathing)

3 sets of $100 \mathrm{~m}$ freestyle stroke, 45 seconds break (emphasis is placed on the coordination of arms and legs movements with breathing)

$>3$ sets of $100 \mathrm{~m}$ breaststroke, 45 seconds break (emphasis is placed on the coordination of arms and legs movements with breathing)

Recovery $200 \mathrm{~m}$ breaststroke or backstroke 
Easy stretching outside the pool for 5-10 minutes.

Week IV

$>$ Warm-up outside the pool 5-10 minutes (gymnastics exercises and active stretching)

Warm-up in the water $200 \mathrm{~m}$., in the styles known by each individual.

$>$ Freestyle stroke 50m, 100m, 150m, $100 \mathrm{~m}, 50 \mathrm{~m}$, medium pace with a 45 seconds break between the sets

$>$ Breaststroke $50 \mathrm{~m}, 100 \mathrm{~m}, 150 \mathrm{~m}, 100 \mathrm{~m}$, $50 \mathrm{~m}$, medium pace with a 45 seconds break between the sets

$>$ Recovery $200 \mathrm{~m}$ breaststroke or backstroke

Easy stretching outside the pool for 5-10 minutes.

\section{Week V}

$>$ Warm-up outside the pool 5-10 minutes (gymnastics exercises and active stretching)

$>$ Warm-up in the water $200 \mathrm{~m}$., in the styles known by each individual.

> Freestyle stroke $50 \mathrm{~m}, 100 \mathrm{~m}, 200 \mathrm{~m}$, $100 \mathrm{~m}, 50 \mathrm{~m}$, medium pace with a 45 seconds break between the sets

> Breaststroke $50 \mathrm{~m}, 100 \mathrm{~m}, 200 \mathrm{~m}, 100 \mathrm{~m}$, $50 \mathrm{~m}$, medium pace with a 45 seconds break between the sets

> Recovery $200 \mathrm{~m}$ breaststroke or backstroke

$>$ Easy stretching outside the pool for 510 minutes.

Week VI

> Warm-up outside the pool 5-10 minutes (gymnastics exercises and active stretching)

$>$ Warm-up in the water $200 \mathrm{~m}$., in the styles known by each individual.

$>5$ sets of $100 \mathrm{~m}$ freestyle, medium pace with a 45 seconds break

$>5$ sets of $200 \mathrm{~m}$ freestyle, medium pace with a 1 minute break

$>$ Recovery $200 \mathrm{~m}$ breaststroke or backstroke

Easy stretching outside the pool for 5-10 minutes

Week VII
Warm-up outside the pool 5-10 minutes (gymnastics exercises and active stretching)

Warm-up in the water $200 \mathrm{~m}$., in the styles known by each individual.

4 sets of $50 \mathrm{~m}$ freestyle stroke, increased pace with a 30 seconds break between the sets

4 sets of $100 \mathrm{~m}$ freestyle stroke, increased pace with a 1 minute break between the sets

2 sets of $400 \mathrm{~m}$ freestyle stroke, medium pace with a 2 minutes break between the sets

$100 \mathrm{~m}$ breaststroke, medium pace

4 sets of $50 \mathrm{~m}$ freestyle stroke, increased pace with a 30 seconds break between the sets

Recovery $100 \mathrm{~m}$ breaststroke or backstroke

Easy stretching outside the pool for 5-10 minutes

Week VIII

$>$ Warm-up outside the pool 5-10 minutes (gymnastics exercises and active stretching)

Warm-up in the water $200 \mathrm{~m}$, in the styles known by each individual.

4 sets of $50 \mathrm{~m}$ freestyle stroke, increased pace with a 30 seconds break between the sets

4 sets of $200 \mathrm{~m}$ freestyle stroke, increased pace with a 1 minute break between the sets

2 sets of $400 \mathrm{~m}$ freestyle stroke, medium pace with a 2 minutes break between the sets

$>100 \mathrm{~m}$ breaststroke, medium pace

$>4$ sets of $50 \mathrm{~m}$ freestyle stroke, increased pace with a 30 seconds break between the sets

Recovery $100 \mathrm{~m}$ breaststroke or backstroke

$>$ Easy stretching outside the pool for 5-10 minutes.

Week IX

Warm-up outside the pool 5-10 minutes (gymnastics exercises and active stretching) 
Warm-up in the water $200 \mathrm{~m}$ (mixed or in the styles known)

4 sets of $100 \mathrm{~m}$ freestyle stroke, increased pace with a 30 seconds break between the sets

4 sets of $200 \mathrm{~m}$ freestyle stroke, increased pace with a 1 minute break between the sets

2 sets of $400 \mathrm{~m}$ freestyle stroke, medium pace with a 2 minutes break between the sets

$>200 \mathrm{~m}$ breaststroke, medium pace

$>4$ sets of $50 \mathrm{~m}$ freestyle stroke, increased pace with a 30 seconds break between the sets

Recovery $100 \mathrm{~m}$ breaststroke or backstroke

Easy stretching outside the pool for 5-10 minutes.

Week X

$>$ Warm-up outside the pool 5-10 minutes (gymnastics exercises and active stretching)

> Warm-up in the water $200 \mathrm{~m}$ (mixed or in the styles known).

4 sets of $100 \mathrm{~m}$ freestyle stroke, increased pace with a 30 seconds break between the sets

4 sets of $200 \mathrm{~m}$ freestyle stroke, increased pace with a 1 minute break between the sets

$>2$ sets of $400 \mathrm{~m}$ freestyle stroke, medium pace with a 2 minutes break between the sets

> $200 \mathrm{~m}$ breaststroke, medium pace

4 sets of $50 \mathrm{~m}$ freestyle stroke, increased pace with a 30 seconds break between the sets

Recovery $100 \mathrm{~m}$ breaststroke or backstroke

Easy stretching outside the pool for 5-10 minutes.

Week XI

D Warm-up outside the pool 5-10 minutes (gymnastics exercises and active stretching)

Warm-up in the water $200 \mathrm{~m}$ (mixed or in the styles known)
4 sets of $100 \mathrm{~m}$ freestyle stroke, increased pace with a 30 seconds break between the sets

$200 \mathrm{~m}$ breaststroke, medium pace

4 sets of $400 \mathrm{~m}$ freestyle stroke, medium pace with a 2 minutes break between the sets

Recovery $100 \mathrm{~m}$ breaststroke or backstroke

Easy stretching outside the pool for 5-10 minutes.

Week XII

$>$ Warm-up outside the pool 5-10 minutes (gymnastics exercises and active stretching)

Warm-up in the water $200 \mathrm{~m}$ (mixed or in the styles known)

\section{M FREESTYLE STROKE} TESTING

Recovery $150 \mathrm{~m}$ breaststroke or backstroke

Easy stretching outside the pool for 5-10 minutes.

„In turn these content and instruction nal strategies can be converted into training programs to ensure instructional objectives set." [4]

\section{Presentation of research data}

In this research we applied the training program to improve the freestyle swimming technique for military students on a number of 80 male students from the second year of study. In order to be able to compare the results and the impact of the centralized training program, we also used a control group of 80 male second-year students.

It should be mentioned that both in the experimental group and in the testing group there were subjects who knew the procedure well but also subjects who knew how to swim but who were tested for swimming for the first time.

All subjects were tested at the beginning of October on a $50 \mathrm{~m}$ freestyle stroke distance, this being the initial test. In the following months: November, December, January, those in the experiment group used the centralized program in their 
training, while those in the control group only attended the classes scheduled in their curriculum.

Testing shows the following graphs with the times recorded by the two groups.

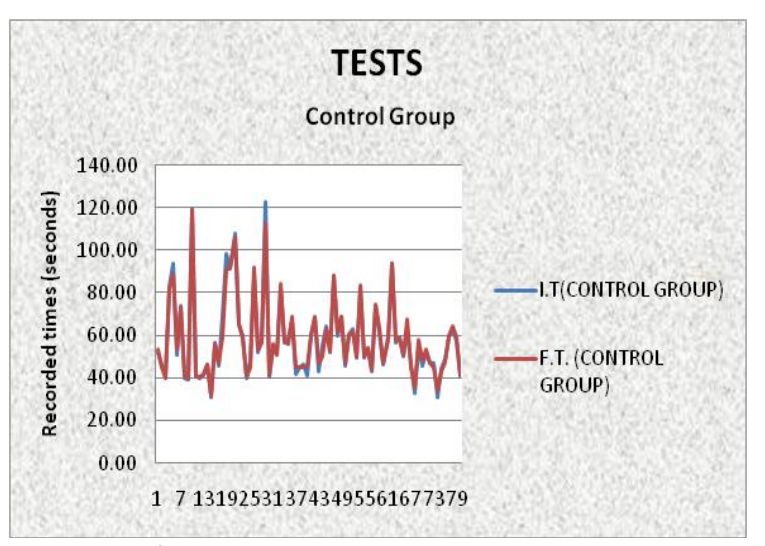

Chart no. 1

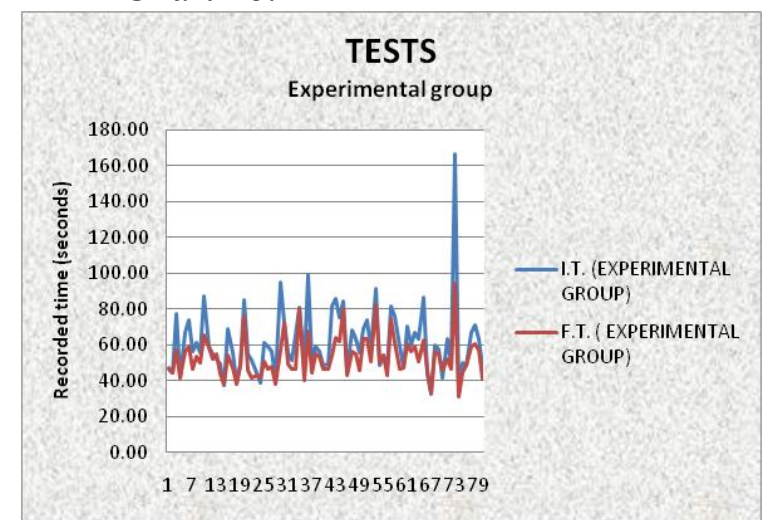

Chart no. 2

After recording the data from the final tests we obtained the following graph which reveals the difference that is very well observed between the two groups.

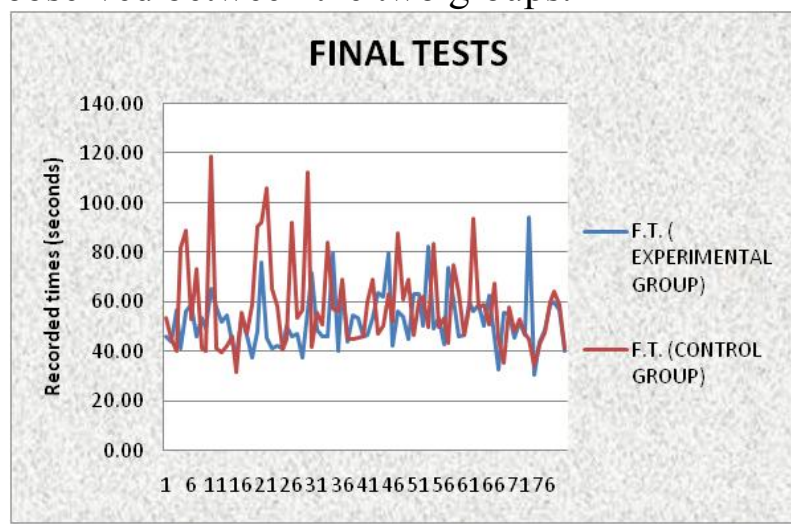

Chart no. 3

Below we present the statistical data we have calculated from the tests of the two groups.
Table no. 1

\begin{tabular}{|lr|r|r|r|}
\cline { 2 - 5 } \multicolumn{1}{c|}{} & \multicolumn{2}{c|}{ Experimental } & \multicolumn{2}{c|}{ Control } \\
\cline { 2 - 5 } \multicolumn{1}{c|}{} & \multicolumn{1}{c|}{ TI } & \multicolumn{1}{c|}{ TF } & \multicolumn{1}{c|}{ TI } & \multicolumn{1}{c|}{ TF } \\
\hline Mean & 61.28 & 52.86 & 58.31 & 58.44 \\
\hline Standard Error & 2.14 & 1.28 & 2.15 & 2.03 \\
\hline Median & 57.62 & 50.61 & 54.00 & 53.76 \\
\hline Mode & 59.47 & - & 82.29 & 53.19 \\
\hline Standard Deviation & 19.10 & 11.47 & 19.22 & 18.14 \\
\hline Sample Variance & 364.71 & 131.61 & 369.43 & 329.17 \\
\hline Kurtosis & 10.49 & 1.80 & 2.03 & 1.60 \\
\hline Skewness & 2.31 & 1.10 & 1.42 & 1.34 \\
\hline Range & 134.07 & 63.41 & 92.42 & 87.12 \\
\hline Minumum & 32.39 & 30.74 & 30.62 & 31.72 \\
\hline Maximum & 166.46 & 94.15 & 123.04 & 118.84 \\
\hline Sum & $4,902.08$ & $4,229.10$ & $4,664.48$ & $4,674.92$ \\
\hline Count & 80.00 & 80.00 & 80.00 & 80.00 \\
\hline Largest (1) & 32.39 & 30.74 & 30.62 & 31.72 \\
\hline Smallest (1) & 166.46 & 94.15 & 123.04 & 118.84 \\
\hline Confidence Level (95,0\%) & 1.96 & 1.96 & 1.96 & 1.96 \\
\hline CV & 0.31 & 0.22 & 0.33 & 0.31 \\
\hline
\end{tabular}

Analyzing the data from the previous table, we observe the following from the mathematical and statistical calculations:

- In the experiment group the coefficient of variability (CV) drops from the initial testing to the final test by 9 units, which means a very homogeneous mean with a difference of 72.31 seconds to the maximum recorded and 1.65 seconds to the minimum recorded.

- For the control group the coefficient of variability $(\mathrm{CV})$ drops from the initial testing to the final test by 2 units, this means a homogeneous mean with a recorded difference of 11.2 seconds to the recorded maximum and -1.1 seconds to the minimum recorded.

\section{Conclusions:}

After applying the training program on the experimental group of this study and the comparison of the results obtained by the statistical analysis between the experimental group and the control group it was found that we have a significant difference recorded in the experimental group.

Thus, we have an important difference in both the coefficient of variability that increases the homogeneity of the mean of the subjects, and at the maximum recorded of 72.31 seconds and the recorded minimum of 1.65 seconds. 
At the same time in the control group, the coefficient of variability changes only by 2 units, and the maximum and minimum differences not only were not significant but were even negative, the maximum being the difference of 11.2 seconds and the minimum -1.1 seconds.
Therefore, we can conclude that the training program showed the expected results and the military students included in this program increased their performance on a distance of $50 \mathrm{~m}$ freestyle stroke swimming.

\section{References}

[1] M. Bíró, L. Révész, P. Hidvégi, 2015, Swimming History Technique Teaching, EKC Líceum Press, Kelet-Magyarországon, p.22

[2] M. Bíró, L. Révész, P. Hidvégi, 2015, op.cit., p.26

[3] Dalton F. E. And Dalton L. C., 2006 Swimming Scientifically Taught A Practical Manual for Young and Old, [EBook \#19065], ISO-8859-1, http://manybooks.net/, p.26

[4] Panait L., Duta D., Negrea V., „Experimental approach regarding investigation level of general physical training for tennis players aged 13 to 14 years", (Ovidius University Annals, Series Physical Education and Sport / Science, Movement And Health, Vol XIII, Issue 2 suppl, 2013, p.284 http://www.analefefs.ro/anale-fefs/2013/s1/pe-autori/29.pdf 